\title{
Phytophthora cinnamomi - new pathogen of high blueberry in Poland
}

\section{Phytophthora cinnamomi - nowy patogen borówki wysokiej w Polsce}

\author{
Leszek Orlikowski*, Magdalena Ptaszek, Beata Meszka
}

\section{Summary}

Phytophthora cinnamomi was isolated from necrotic roots and stem parts of blueberry with aboveground symptoms of chlorosis and reddening of leaves, defoliation, dieback of branches, growth stunting and crown and root rot. The species was also detected from substratum of diseased plants. Other species including Alternaria alternata, Botrytis cinerea and Fusarium avenaceum were isolated rarely. The species isolates from highbush blueberry and cranberry colonized stem parts, roots and leaf blades of host plant. Necrosis spread much faster on inoculated stem parts than blueberry roots. In greenhouse trials isolate from high blueberry was more pathogenic than that from cranberry.

Key words: high blueberry; dieback; Phytophthora cinnamomi; isolates; cultivars; colonisation

\section{Streszczenie}

Phytophthora cinnamomi izolowano z nekrotycznych korzeni i podstawy pędów borówki wysokiej z symptomami zahamowania wzrostu, chlorozy, czerwienienia, zdrobnienia i opadania liści, zamierania pojedynczych pędów i zgnilizny ich podstawy. Patogena stwierdzono również w podłożu pobranym spod chorych roślin. Inne gatunki, tj. Alternaria alternata, Botrytis cinerea i Fusarium avenaceum izolowano rzadko. Izolaty $P$. cinnamomi z borówki wysokiej i żurawiny błotnej kolonizowały fragmenty łodyg, korzenie oraz liście roślin - gospodarzy. Nekroza rozwijała się znacznie szybciej na zainokulowanych fragmentach pędów, aniżeli na korzeniach borówki. W doświadczeniach szklarniowych izolat pochodzący z borówki był bardziej patogeniczny niż kultura z żurawiny.

Słowa kluczowe: borówka wysoka; zamieranie; Phytophthora cinnamomi; izolaty; odmiany; kolonizacja

Instytut Ogrodnictwa

Konstytucji 3 Maja 1/3, 96-100 Skierniewice

*corresponding author: leszek.orlikowski@inhort.pl 


\section{Wstęp / Introduction}

Wyniki opublikowanych dotychczas prac naukowych nad chorobami borówki wysokiej (Vaccinium corymbosum L.) wskazują na duże zagrożenie tego gatunku przez różne patogeny. Już w latach 70. XX wieku Borecki i Pliszka (1978) stwierdzili na borówce zgorzel pędów powodowaną przez Godronia cassandrae. Polashock i wsp. (2005) uznali antraknozę borówki wysokiej, powodowaną przez Colletotrichum acutatum za bardzo groźną chorobę na plantacjach w północnych stanach USA. Opinię tą potwierdzają badania Meszki i Bielenin (2012), wskazujące na występowanie C. acutatum i $C$. gloeosporioides na wszystkich organach nadziemnych roślin, a zwłaszcza owocach, również w warunkach Polski. Wyniki badań Cline i Milholland (1992) wykazały bardzo dużą szkodliwość Botryosphaeria dothidea jako przyczyny zamierania pędów borówki. W grupie grzybów zasiedlających owoce borówki Zalewska i wsp. (2007) wymieniają także Botrytis cinerea, Monilinia fructigena, Topospora myrtilli, Phomopsis archeri i Truncatella angustata. Jednym z bardzo groźnych patogenów borówki jest Phytophthora cinnamomi, przyczyna zgnilizny podstawy pędu i korzeni (Larach i wsp. 2009) lub zgnilizny systemu korzeniowego (Sterne 1982; Bryla i Linderman 2007). Choroba została opisana po raz pierwszy w USA w latach 60. XX wieku przez Royle i Hickman (1963) oraz Clayton i Haasis (1964). Od tego czasu stwierdzono ją również we Włoszech (Tamietti 2003), Chile (Larach i wsp. 2009) i różnych stanach Ameryki Północnej (Milholland 1975; Sterne 1982; Smith 2006, 2008).

W 2014 roku na 2-letniej plantacji borówki wysokiej zaobserwowano objawy zahamowania wzrostu, a następnie stopniowego zamierania roślin. Celem badań była izolacja i identyfikacja czynnika powodującego chorobę (1) oraz określenie jego patogeniczności w stosunku do różnych odmian borówki wysokiej (2).

\section{Materiały i metody / Materials and methods}

Materiał roślinny. Przedmiotem badań były 22 rośliny borówki wysokiej odmiany Sierra, wykazujące zróżnicowane objawy chorobowe, pobrane ze szkółki kontenerowej. Na 3 roślinach widoczne było zdrobnienie i przejaśnienie liści na pojedynczych pędach, ich żółknięcie i opadanie. Na 5 roślinach, na pojedynczych pędach liście były w większości czerwonawe, a przy dotknięciu opadające, podczas gdy na innych jasnozielone. Na pozostałych 14 roślinach pojedyncze pędy były zbrązowiałe lub w części zbrunatniałe. U ich podstawy widoczna była zgnilizna rozszerzająca się ku górze na długości do $3 \mathrm{~cm}$ oraz w kierunku korzeni. System korzeniowy wszystkich analizowanych roślin był silnie zredukowany. Korzenie włośnikowe były zbrunatniałe i rozpadały się. Objawy zgnilizny rozszerzały się na starsze korzenie. Na opadłych liściach widać było nekrotyczne plamy przy ogonkach liściowych, jak również na wierzchołkach.

Analiza mikologiczna porażonych roślin. Chore rośliny pobrane ze szkółki umieszczono w oddzielnych torbach foliowych i przewieziono do laboratorium Pracowni
Chorób Roślin Ozdobnych, Instytutu Ogrodnictwa w Skierniewicach. Z 10 losowo wybranych roślin pobrano próby podłoża ze strefy korzeni w celu izolacji potencjalnego czynnika chorobotwórczego przy zastosowaniu metody pułapkowej (Themann i Werres 1998; Orlikowski i wsp. 2011). Następnie z każdej rośliny odcięto fragmenty korzeni oraz podstawy pędów, a do izolacji mikroorganizmów z porażonych tkanek zastosowano metodę opisaną przez Orlikowskiego i Szkutę (2005). Po umyciu ich pod bieżącą wodą, opłukaniu w wodzie destylowanej i osuszeniu pomiędzy warstwami sterylnej bibuły filtracyjnej, fragmenty około $5 \mathrm{~mm}$, po ich uprzednim odkażeniu nad płomieniem palnika, wykładano na pożywkę ziemniaczano-glukozową (PDA - Potato Dextrose Agar) w szalkach Petriego o średnicy $90 \mathrm{~mm}$. Po 2 dniach inkubacji $\mathrm{w}$ temperaturze $25^{\circ} \mathrm{C} \mathrm{w}$ ciemności, fragmenty pożywki przerośnięte strzępkami przeszczepiano na skosy $\mathrm{z}$ pożywką PDA. Po następnych 7 dniach inkubacji uzyskanych kultur, segregowano je na grupy na podstawie wyglądu kolonii. Wybrane izolaty reprezentacyjne oznaczano do rodzajów i gatunków na podstawie ich cech morfologicznych (Erwin i Ribeiro 1996) oraz przy zastosowaniu metod molekularnych $\mathrm{w}$ reakcji PCR (polymerase chain reaction) ze starterami gatunkowo specyficznymi DC9 i DC5 dla P. cinnamomi (Boersma i wsp. 2000). Podobnie postępowano z kulturami uzyskanymi z prób podłoża.

Ocena patogeniczności izolatów $P$. cinnamomi w stosunku do odmian borówki wysokiej. Oceniano chorobotwórczość izolatów $P$. cinnamomi uzyskanych z porażonej podstawy pędów borówki i żurawiny (Vaccinium oxycoccus L.). Kultury do inokulacji rosły na pożywce PDA w temperaturze $25^{\circ} \mathrm{C}$ przez 7 dni. Po tym czasie wycinano krążki pożywki przerośnięte strzępkami patogena i przenoszono je na fragmenty podstawy łodyg, korzeni i blaszek liściowych pobranych z 8 odmian borówki wysokiej, wyłożonych w kuwetach fotograficznych $(35 \times 25 \times 5 \mathrm{~cm})$ na 2 warstwach wilgotnej, sterylnej bibuły filtracyjnej, przykrytych cienką nylonową siatką. Kuwety okrywano folią i inkubowano na stołach laboratoryjnych. Po 3 i 6 dniach inkubacji mierzono długość powstałych nekroz na fragmentach łodyg i korzeni oraz średnicę nekrotycznych plam na liściach.

W doświadczeniach szklarniowych, 1-roczne rośliny borówki odmiany Sierra ustawiono w szklarni pod tunelem, a następnie zainokulowano pędy u ich nasady 2 izolatami P. cinnamomi, z rośliny - gospodarza oraz z żurawiny. Po 5 i 10 dniach inkubacji w temperaturze $18-25^{\circ} \mathrm{C}$ zmierzono długości powstałych nekroz.

Doświadczenia założono w układzie całkowicie losowym w 4 powtórzeniach, po 5 fragmentów łodyg i korzeni, 5 blaszek liściowych i 5 roślin. Powtórzono je 2-krotnie w odstępie 2-tygodniowym. Wyniki z przeprowadzonych doświadczeń opracowano statystycznie metodą analizy wariancji. Istotność różnic pomiędzy średnimi $(\alpha=0,05)$ oceniono testem Duncana.

\section{Wyniki i dyskusja / Results and discussion}

Z wyłożonych na pożywkę PDA fragmentów porażonych korzeni i podstawy pędów z 22 roślin wyizolowano 
Alternaria alternata, B. cinerea, Cladosporium herbarum, Chaetomium globosum, Fusarium avenaceum, Mucor spp., Penicillium spp., P. cinnamomi i Trichoderma spp. Gatunek $P$. cinnamomi izolowano z tkanek 21 roślin, podczas gdy pozostałe grzyby występowały sporadycznie.

Zastosowanie pułapek z liści różanecznika do wykrywania Phytophthora sp. w podłożu, pobranym ze strefy korzeni 10 porażonych roślin borówki wysokiej, pozwoliło na wykrycie $P$. cinnamomi we wszystkich badanych próbach. Izolacja $P$. cinnamomi z 21 roślin borówki oraz z 10 prób podłoża była powodem podjęcia dalszych badań $\mathrm{z}$ tym gatunkiem oraz $\mathrm{z}$ włączeniem dodatkowego izolatu pochodzącego z żurawiny błotnej.

W pierwszej części badań zakażono łodygi i korzenie 3 odmian borówki: Brigitte, Darrow, Goldtraube (rys. 1, 2), a następnie po stwierdzeniu, iż badany gatunek Phytophthora kolonizuje tkanki roślin, zakażono łodygi i korzenie kolejnych 5 odmian (Bluecrop, Chandler, Nelson, Sierra i Torro) (rys. 3, 4). Niezależnie od źródła izolatu, P. cinnamomi kolonizował części łodyg borówki (rys. 1). Po 6 dniach od inokulacji zgnilizna wynosiła od 23 do $36 \mathrm{~mm}$. Na odmianie Darrow, izolat $\mathrm{z}$ borówki kolonizował tkanki istotnie szybciej niż ten z żurawiny. Odwrotną zależność stwierdzono na odmianie Goldtraube (rys. 1). Na inokulowanych korzeniach, nekroza widoczna była na długości od 14,4 do $27,7 \mathrm{~mm}$, przy czym izolat z żurawiny kolonizował tkanki wszystkich testowanych odmian borówki istotnie szybciej niż ten z borówki (rys. 2).

W drugiej części badań oceniono stopień kolonizowania tkanek pozostałych 5 odmian borówki wysokiej (rys. 3, 4, tab. 1). Okazało się, że łodygi odmiany Nelson były kolonizowane najwolniej, a odmiany Torro najszybciej. Nie stwierdzono natomiast istotnych różnic pomiędzy

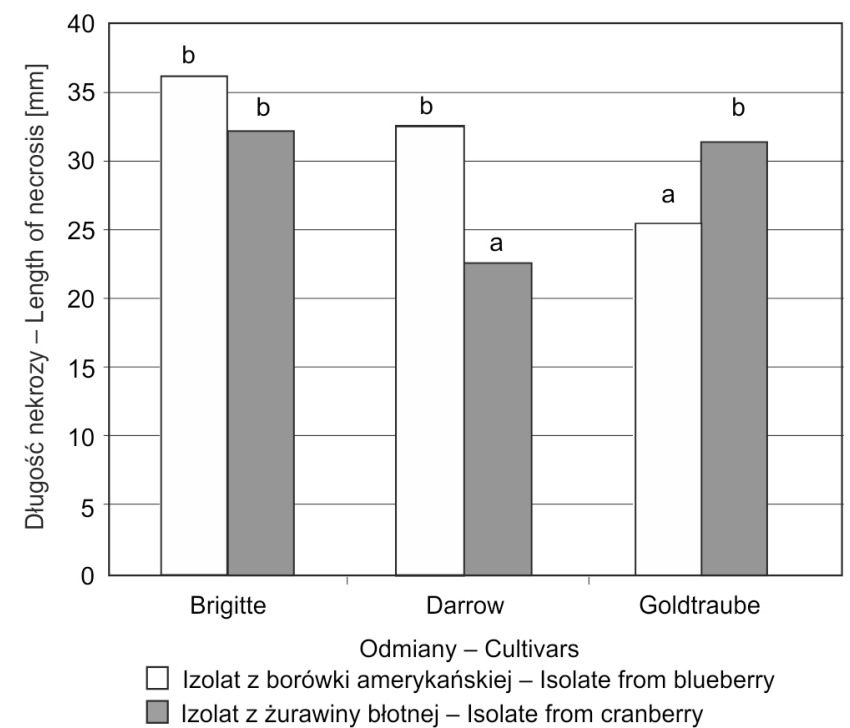

Średnie w słupkach, oznaczone tą samą literą nie różnią się istotnie (5\%) według testu Duncana

Means in columns, followed by the same letter do not differ (5\%) according to Duncan's multiple range test

Rys. 1. Kolonizacja części łodyg borówki wysokiej przez Phytophthora cinnamomi w zależności od źródła izolatu i odmiany po 6 dniach od inokulacji

Fig. 1. Colonization of highbush blueberry stem parts by Phytophthora cinnamomi in relations to isolates source and cultivars 6 days after inoculation

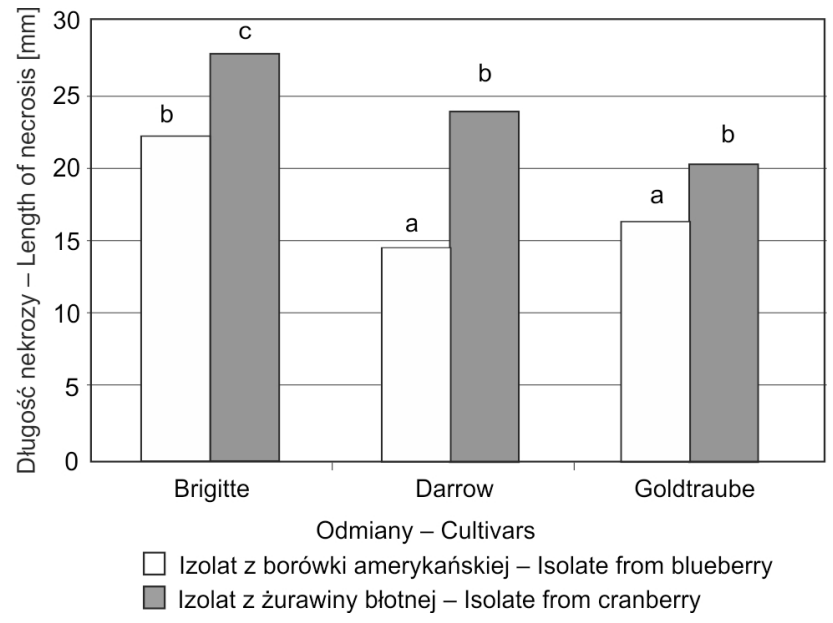

Średnie w słupkach, oznaczone tą samą literą nie różnią się istotnie (5\%) według testu Duncana

Means in columns, followed by the same letter do not differ (5\%) according to Duncan's multiple range test

Rys. 2. Kolonizacja korzeni borówki wysokiej przez Phytophthora cinnamomi w zależności od źródła izolatu i odmiany po 6 dniach od inokulacji

Fig. 2. Colonization of highbush blueberry roots by Phytophthora cinnamomi in relations to isolates source and cultivars 6 days after inoculation

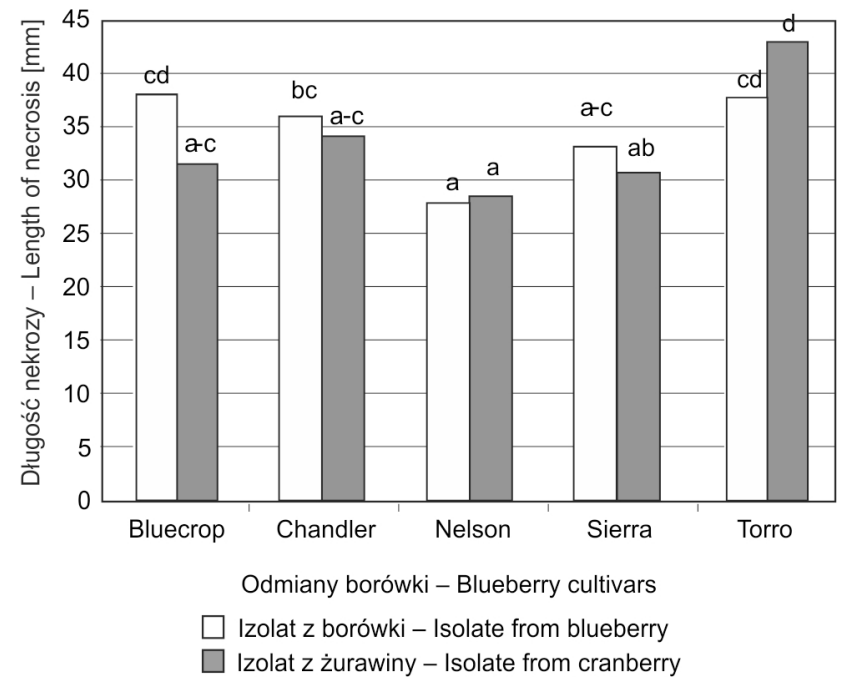

Średnie w słupkach, oznaczone tą samą literą nie różnią się istotnie (5\%) według testu Duncana

Means in columns, followed by the same letter do not differ (5\%) according to Duncan's multiple range test

Rys. 3. Wpływ źródła izolatów Phytophthora cinnamomi i odmiany borówki wysokiej na kolonizację części łodyg po 6 dniach inkubacji

Fig. 3. Influence of Phytophthora cinnamomi isolates source and highbush blueberry cultivars on colonization of stem parts 6 days after inoculation

tempem kolonizacji łodyg w zależności od zastosowanego izolatu (rys. 3). Analiza zasiedlenia korzeni borówki przez $P$. cinnamomi wskazuje, że objawy zgnilizny postępowały wolniej aniżeli na częściach łodyg (od 15 do 24,5 mm) (rys. 4). Izolat $\mathrm{z}$ żurawiny kolonizował istotnie wolniej korzenie odmiany Bluecrop, natomiast istotnie szybciej korzenie odmiany Nelson (rys. 4). Izolat pochodzący z bo- 
rówki kolonizował korzenie wszystkich badanych odmian w podobnym stopniu (rys. 4).

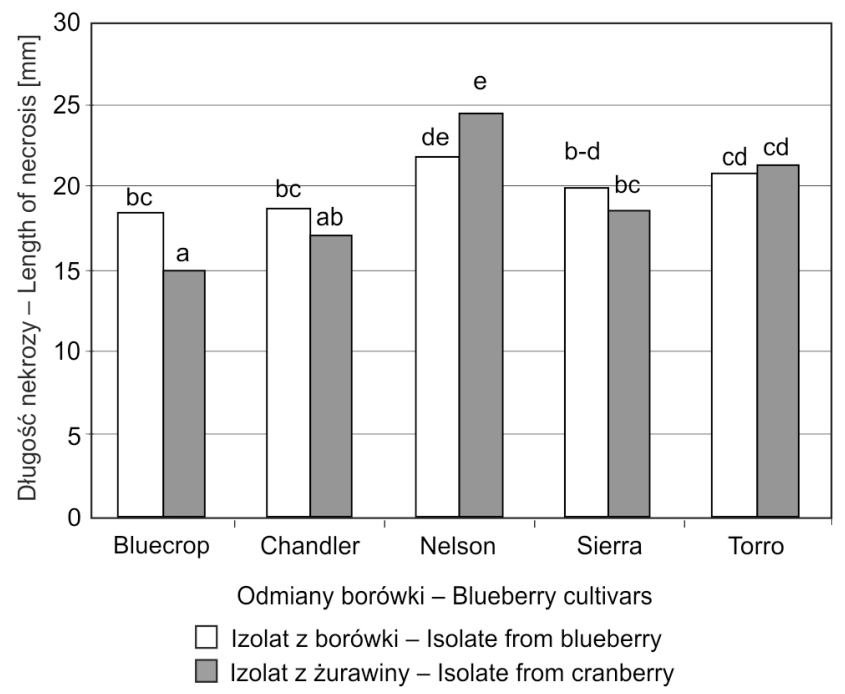

Średnie w słupkach, oznaczone tą samą literą nie różnią się istotnie $(5 \%)$ według testu Duncana

Means in columns, followed by the same letter do not differ $(5 \%)$ according to Duncan's multiple range test

Rys. 4. Wpływ źródła izolatów Phytophthora cinnamomi i odmiany borówki na kolonizację korzeni po 6 dniach inkubacji

Fig. 4. Influence of Phytophthora cinnamomi isolates source and highbush blueberry cultivars on colonisation of roots 6 days after inoculation

Uzyskane dane wskazują, że oba izolaty $P$. cinnamomi kolonizowały liście 5 odmian borówki (tab. 1), ale po 6 dniach inkubacji nekroza o średnicy od 6 do $15,4 \mathrm{~mm}$ rozwijała się wolniej aniżeli na częściach łodyg i korzeniach (rys. 3, 4). Izolat $\mathrm{z}$ żurawiny kolonizował istotnie najwolniej blaszki liściowe odmiany Nelson (tab. 1).

W doświadczeniu szklarniowym, założonym na 1-rocznych sadzonkach borówki, izolaty $P$. cinnamomi z rośliny - gospodarza i żurawiny kolonizowały także tkanki podstawy pędu. Już po 3 dniach widoczne były kilkumilimetrowej średnicy plamy, a po następnych 2 dniach nekroza widoczna była na długości 9-14,5 mm podstawy pędów (rys. 5). Po upływie 10 dni nastąpił dalszy rozwój objawów choroby. Zarówno po 5, jak i 10 dniach nekroza rozwijała się istotnie szybciej na roślinach inokulowanych izolatem z borówki wysokiej (rys. 5).

Analiza porażonych roślin wykazała występowanie podobnych symptomów chorobowych, jak te opisane przez Bryla i Lindermana (2007), Smitha (2008) oraz Laracha i wsp. (2009) na borówkach uprawianych w różnych stanach USA i w Chile. Autorzy zwracają uwagę przede wszystkim na silne zahamowanie rozwoju roślin, widoczne w formie drobnienia liści, ich żółknięcia lub czerwienienia, brak nowych przyrostów, zgniliznę korzeni i silną redukcję systemu korzeniowego. Obserwacje przeprowadzone przez Sterne (1982) wskazują na szczególną podatność młodych roślin borówki (w wieku od 1 do 3 lat) na porażenie przez $P$. cinnamomi. Autor stwierdził prawie całkowite kolonizowanie korzeni przez patogena i ich czernienie. Takich symptomów nie odnotowano na roślinach $\mathrm{w}$ badaniach własnych, gdzie obiektem zainteresowania były 2-letnie borówki. Różnice w natężeniu objawów na korzeniach wynikają zapewne ze stopnia porażenia roślin pobranych do badań

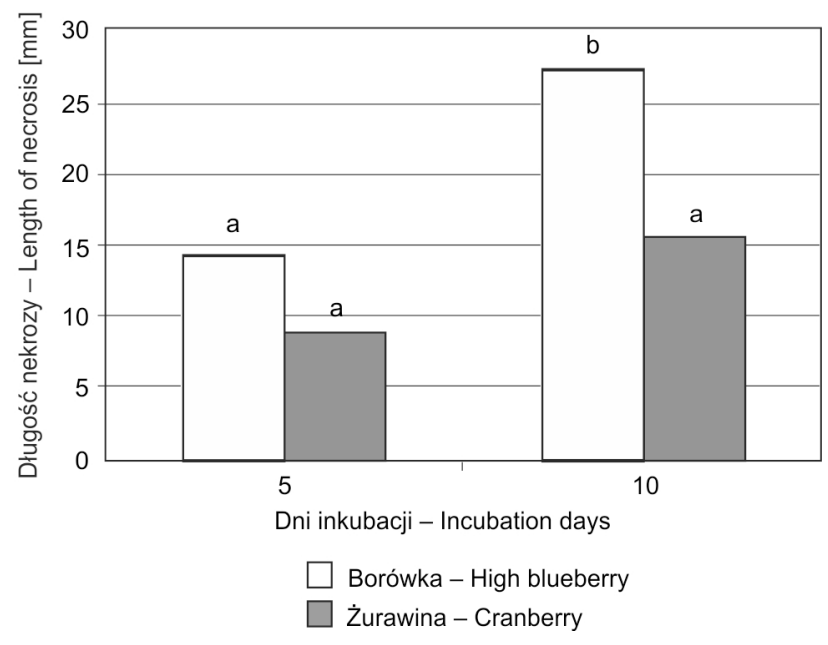

Średnie w słupkach, oznaczone tą samą literą nie różnią się istotnie $(5 \%)$ według testu Duncana

Means in columns, followed by the same letter do not differ (5\%) according to Duncan's multiple range test

Rys. 5. Współzależność między źródłem izolatów, czasem inkubacji a kolonizacją podstawy pędów borówki wysokiej przez Phytophthora cinnamomi; doświadczenie szklarniowe

Fig. 5. Relationship between isolates source, incubation time and colonisation of highbush blueberry stem bases by Phytophthora cinnamomi; greenhouse trial

Tabela 1. Współzależność pomiędzy źródłem izolatów Phytophthora cinnamomi, odmianami borówki wysokiej a kolonizacją blaszek liściowych; średnica nekrozy po 6 dniach od inokulacji [mm]

Table 1. Relationship between Phytophthora cinnamomi isolates source, cultivars and colonization of highbush blueberry leaf blades; diameter of necrotic spots 6 days after inoculation [mm]

\begin{tabular}{l|c|c|c|c|c}
\hline \multirow{2}{*}{$\begin{array}{c}\text { Źródło izolatów } \\
\text { Source of isolates }\end{array}$} & Bluecrop & Chandler & Nelson & Sierra & Torro \\
\cline { 2 - 6 } & $10,4 \mathrm{~b}$ & $9,5 \mathrm{~b}$ & $14,7 \mathrm{~cd}$ & $12,5 \mathrm{~b}-\mathrm{d}$ & $11,2 \mathrm{bc}$ \\
\hline Vaccinium corymbosum & $9,4 \mathrm{~b}$ & $15,4 \mathrm{~b}$ & $6,0 \mathrm{a}$ & $12,6 \mathrm{~b}-\mathrm{d}$ & $10,3 \mathrm{~b}$ \\
\hline Vaccinium oxycoccus & &
\end{tabular}

Średnie oznaczone tą samą literą nie różnią się istotnie $(5 \%)$ według testu Duncana

Means followed by the same letter do not differ (5\%) according to Duncan's multiple range test 
Smith (2008) podkreśla, że zgnilizna korzeni występuje szczególnie w dużym nasileniu, gdy borówkę uprawia się na wilgotnych, słabo drenowanych glebach. $Z$ badań Bryla i Lindermana (2007) wynika, że bardzo duży wpływ na rozwój symptomów, powodowanych przez $P$. cinnamomi, ma sposób nawadniania roślin. Nasilenie objawów choroby było około 2-krotnie niższe, gdy deszczowano rośliny w porównaniu do nawadniania kropelkowego. Autorzy thumaczą to mniejszą ilością wody w powierzchniowej warstwie gleby i przez to mniej korzystnymi warunkami dla rozwoju patogena. Berhardt i Grogan (1982) oraz Duniway (1983) wskazują również na ograniczenie tworzenia zoosporangiów P. cinnamomi i rozprzestrzeniania zoospor przy nawadnianiu roślin przez ich spryskiwanie.

Dane uzyskane przez Milholland (1975), de Silva i wsp. (1999) oraz Larach i wsp. (2009) wskazuja na podatność większości uprawianych odmian borówki na P. cinnamomi. Badania własne są tego potwierdzeniem. Jednakże Larach i wsp. (2009) podają, że odmiana Torro charakteryzuje się odpornością na patogena, podczas gdy w niniejszych doświadczeniach łodygi tej odmiany były wrażliwe na $P$. cinnamomi. Wyniki uzyskane z badań nad kolonizacją odmian borówki przez izolaty $P$. cinnamomi $\mathrm{z}$ rośliny - gospodarza oraz żurawiny błotnej wskazują na niewielkie, ale w niektórych kombinacjach istotne różnice w rozwoju nekrozy na zainokulowanuych organach. Izolat z żurawiny błotnej kolonizował korzenie odmian Brigitte, Darrow i Goldtraube istotnie szybciej aniżeli kultura $\mathrm{z}$ borówki wysokiej. W doświadczeniach $\mathrm{z}$ fragmentami łodyg, były one kolonizowane przez ten izolat istotnie szybciej tylko u odmiany Goldtraube. Prawdopodobnie czynnikiem różnicującym jest stopień zdrewnienia tkanek analizowanych odmian pobranych do badań. W doświadczeniach Milhollanda (1975), 4 izolaty z różnych roślin wrzosowatych kolonizowały 4 odmiany borówki, przy czym średni stopień ich porażenia był istotnie wyższy przy zakażeniu przez kulturę z borówki wysokiej. Wyniki uzyskane $\mathrm{z}$ badań prowadzonych $\mathrm{w}$ warunkach szklarniowych potwierdzają te dane oraz wskazują na bardzo duże zagrożenie borówki wysokiej przez P. cinnamomi. Patogen może być szybko rozprzestrzeniony w nasadzeniach $\mathrm{z}$ wodą do podlewania (Sterne 1982) i przetrwać bez obecności rośliny żywicielskiej przez kilka lat (Zentmyer i Mircetich 1966).

Uzyskane wyniki badań są pierwszymi danymi w Polsce o występowaniu i zagrożeniu borówki wysokiej przez P. cinnamomi.

\section{Wnioski / Conclusions}

1. P. cinnamomi okazał się dominującym gatunkiem wśród mikroorganizmów izolowanych z porażonych korzeni i podstawy pędów borówki wysokiej.

2. P. cinnamomi zasiedlał wszystkie próby podłoża pobranego ze strefy korzeni porażonych roślin borówki.

3. Izolaty P. cinnamomi pochodzące $\mathrm{z}$ borówki wysokiej i żurawiny błotnej kolonizowały tkanki łodyg, korzeni i liści borówki.

4. Badany gatunek jest przyczyną zahamowania wzrostu i rozwoju borówki wysokiej, więdnięcia części pędów, żółknięcia i czerwienienia liści, zgnilizny korzeni, podstawy pędów i zamierania roślin.

\section{Literatura / References}

Berhardt E.A., Grogan R.G. 1982. Effect of soil matric potential on the formation and indirect germination of sporangia of Phytophthora parasitica, P. capsici, and P. cryptogea. Phytopathology 72: 507-511.

Boersma J.G., Cooke D.E.L., Sivastihamparam K. 2000. A survey of wildflower forms in the south-west of Western Australia for Phytophthora spp. associated with root rots. Australian Journal of Experimental Agriculture 40: 1011-1019.

Borecki Z., Pliszka K. 1978. Zgorzel pędów borówki wysokiej wywołana przez grzyb Godronia cassandrae (Peck.) Groves. Acta Agrobotanica 31: 159-171.

Bryla D.R., Linderman R.G. 2007. Implications of irrigation method and amount of water application on Phytophthora and Pythium infection severity of root rot in highbush blueberry. HortScience 42 (6): 1463-1467.

Clayton C.N., Haasis F.A. 1964. Blueberry root-rot caused by Phytophthora cinnamomi in North Carolina. Plant Disease Reporter 48: $460-461$.

Cline W.O., Milholland R.D. 1992. Root dip treatments for controlling blueberry stem blight caused by Botryosphaeria dothidea in container-grown nursery plants. Plant Disease 76: 136-138.

de Silva A., Patterson K., Rothrock C., McNew R. 1999. Phytophthora root rot of blueberry increases with frequency of flooding. HortScience 34: 693-695.

Duniway J.M. 1983. Role of physical factors in the development of Phytophthora diseases. p. 175-187. In: "Phytophthora: its Biology, Taxonomy, Ecology, and Pathology” (D.C. Erwin., S. Bartnicki-Garcia, P.H. Hsiao, eds.). APS Press, St. Paul, MN, 392 pp.

Erwin D.C., Ribeiro O.K. 1996. Phytophthora diseases Worldwide. APS Press, St. Paul, MN, 562 pp.

Larach A., Besoain X., Salgado E. 2009. Crown and root rot of highbush blueberry caused by Phytophthora cinnamomi and P. citrophthora and cultivar sensitivity. Ciencia e Investigación Agraria 36 (3): 433-442.

Meszka B., Bielenin A. 2012. Antraknoza borówki wysokiej, występowanie, szkodliwość i możliwości zwalczania. [Blueberry antracnose, occurence, harmfulness and control possibilities]. Progress in Plant Protection/Postępy w Ochronie Roślin 52 (1): 88-91.

Milholland R.D. 1975. Pathogenicity and histopathology of Phytophthora cinnamomi on highbush and rabbiteye blueberry. Phytopathology 65: 789-793.

Orlikowski L.B., Ptaszek M., Trzewik A., Orlikowska T. 2011. Przydatność pułapek liściowych do detekcji Phytophthora spp. z wody. Sylwan 155 (7): 493-499.

Orlikowski L.B., Szkuta G. 2005. Occurrence of Phytophthora citrophthora on Syringa vulgaris in Poland. Acta Mycologica 40 (2): $175-180$. 
Polashock J., Ehlenfeldt M.K., Stretch A.W., Kramer M. 2005. Antracnose fruit rot resistance in blueberry cultivars. Plant Disease 89: $33-38$.

Royle D.J., Hickman C.J. 1963. Phytophthora cinnamomi on highbush blueberry. Plant Disease Reporter 47: $266-268$.

Smith B.J. 2006. Phytophthora root rot and Botryosphaeria stem blight: Important diseases of southern highbush blueberries in the southern United States. Acta Horticulturae 715: 473-480.

Smith B.J. 2008. Cultural practices and chemical treatments affect Phytophthora root rot severity of blueberries grown in South Missisippi. International Journal of Fruit Science 8 (3): 173-181.

Sterne R.E. 1982. Phytophthora root rot of blueberry in Arkansas. Plant Disease 66: 604-605.

Tamietti G. 2003. First report of Phytophthora cinnamomi on high-bush blueberry in Italy. Plant Disease 87 (4), p. 451.

Themann K., Werres S. 1998. Verwendung von Rhododendronblättern zum Nachweis von Phytophthora-Arten in Wurzeln- und Bodenproben. Nachrichtenblatt des Deutschen Pflanzenschutzdienstes 50: 37-45.

Zalewska E., Król E., Machowicz-Stefaniak Z. 2007. Grzyby zasiedlające owoce borówki wysokiej (Vaccinium corymbosum L.) uprawianej w południowo-wschodniej Polsce. [Fungi colonizing the fruits of blueberry (Vaccinium corymbosum L.) cultivated in south-eastern Poland]. Progress in Plant Protection/Postępy w Ochronie Roślin 47 (2): 380-384.

Zentmyer G.A., Mircetich S.M. 1966. Saprophytism and persistence in soil by Phytophthora cinnamomi. Phytopathology 56: 710-712. 